\title{
Does Argan Oil Supplementation Affect Metabolic Parameters and Behavior in Wistar Rats?
}

\author{
Rim Bousalham 1 , Laila Jahidi Rhazali², Amal Harmouch ${ }^{2}$, Hamid Lotfi ${ }^{3}$, \\ Bouchra Benazzouz ${ }^{1}$, Aboubaker El Hessni' ${ }^{1}$, Ali Ouichou ${ }^{1}$, Omar Akhouayri ${ }^{1}$, \\ Abdelhalem Mesfioui ${ }^{1}$ \\ ${ }^{1}$ Laboratory of Genetic, Neuroendocrinology and Biotechnology, Faculty of Sciences, Ibn Tofail University, \\ Kenitra, Morocco \\ ${ }^{2}$ Laboratory RHAZALI of Pathological Anatomy, Kenitra, Morocco \\ ${ }^{3}$ Laboratory DHL of Biomedical Analysis, Kenitra, Morocco \\ Email: rim.bousalham@gmail.com
}

Received 11 February 2014; accepted 22 June 2015; published 25 June 2015

Copyright (C) 2015 by authors and Scientific Research Publishing Inc.

This work is licensed under the Creative Commons Attribution International License (CC BY).

http://creativecommons.org/licenses/by/4.0/

(c) (i) Open Access

\begin{abstract}
Argan oil is renowned for its particular biochemical profile: high-fat oleic and linoleic acids, tocopherols, sterols, polyphenols. This composition gives it nutritional, therapeutic and preventive properties against dermatological, metabolic and proliferative diseases. The composition of argan oil assigns its benefits to mental health; it would be provided with possible effects on the prevention and/or cure of stress related disorder. This work aims to evaluate the impact of argan oil dietary on the behavioral response, biochemical and hematological constants and histological profiles of adrenal involved in emotional responses to stress. The variation of these parameters was evaluated in Wistar rats receiving dietary $10 \mathrm{ml} / \mathrm{Kg} /$ day of argan oil, starting from weaning, for 13 weeks. Our results show that supplementation has resulted in an increase in locomotor activity, reduced sensitivity to frightening environments with sex dependent variation. Moreover, lipid markers, corticosterone and lymphocytes show a rising trend. If the important role of argan oil diet in cardio-metabolic health is generally well recognized; for mental health, it is the first study that needs further investigation linking between the nervous system, inflammation parameters and metabolism.
\end{abstract}

\section{Keywords}

Argan Oil, Supplementation, Wistar Rats, Biochemical Profile, Hematological Profile, Behavioral Tests, Histological Study, Stress Related Disorders, Epigenetic 


\section{Introduction}

Argan oil obtained from Argania spinosa L. seeds is eaten raw in southwest of Morocco. It has been commonly used in traditional medicine as natural remedy since several centuries. Nowadays, it has been known for its various pharmacological properties for its cosmetic, bactericide and fungicide properties [1].

Chemical analysis of this oil highlighted a glyceride fraction (99\%) that is mainly rich in polyunsaturated fatty acids like oleic C18:1 (47.7\%) and linoleic C18:2 (29.3\%) acids [2]. Studies with the unsaponifiable fraction revealed that argan oil is rich in tocopherol $(62.0 \mathrm{mg} / 100 \mathrm{~g})$. This compound makes argan oil a very important source of Vitamin E [3].

Various studies conducted in vitro or on human and animal models suggest that argan oil could play a beneficial role in cardiovascular diseases prevention and its consumption could protect against atherosclerosis and cancer via a variety of biological mechanisms.

The potential health benefits of argan oil were first shown in the treatment of the hyperlipidemia and hypercholesterolemia. Indeed, total cholesterol, low density lipoprotein (LDL)-cholesterol, triglycerides and body weight decreased while high density lipoprotein (HDL)-cholesterol concentration remained unaltered in rodents supplemented by argan oil [4]. These effects have been related with the polyunsaturated fatty acids and other constituents of argan oil.

Argan oil composition has also been correlated to cancer chemoprotective effects especially due to the abundance of tocopherol, one of the much potent antioxidants [5].

In addition, argan oil has an antidiabetic effect which is likely to be its most anciently claimed pharmacological effects; however, the mechanism linking argan oil consumption and blood glucose level regulation remains unknown [6].

Consumption of argan oil with its unique profile of tocopherols, sterols, phenolic compounds and especially fatty acids should confer valuable mental health benefit. In particular, some compounds of argan oil may have preventive effects against stress since 1) their transport across the blood-brain barrier is easily done [7]; 2) they have shown a relevant anti-inflammatory effect [8]: increasing in inflammation markers is one of stress manifestations; also 3) lack of polyunsaturated fatty acids is of aetiological importance in stress-related affective disorder and there are evidences showing the antidepressant effects of omega-3 polyunsaturated fatty acids [9].

In the light of these data, the main proposal of this work was to investigate in Wistar rats the effect of virgin argan oil supplementation on:

- stress related behavior (anxiety and depression);

- adrenal histology;

- some metabolic and blood panel markers.

\section{Materials and Methods}

\subsection{Animals}

All experimental procedures were performed according to the NIH Guide for the Care and Use of Laboratory Animals. The animals used in this study are rats from the wistar strain. They were born, bred and housed on a 12 $\mathrm{h}$ light $/ 12 \mathrm{~h}$ dark cycle, $50 \%$ to $60 \%$ humidity and at a standard temperature $21^{\circ} \mathrm{C} \pm 1{ }^{\circ} \mathrm{C}$. Water and food were provided at libitum.

Male $(\mathrm{N}=6)$ and female $(\mathrm{N}=6)$ rats were aged 22 days (at weaning) when argan oil supplementation began. Rats were treated with argan oil (1 ml/100g weight) daily by oral route [4] [10] during 13 weeks (supplemented group). Control animals were treated orally for the same duration with $\mathrm{NaCl} 0.9 \%$.

\subsection{Argan Oil}

In order to deliver to animals oil with a similar composition to the one used in human's diet, Argan oil used in this work is originated from southwestern Morocco and was extracted from fresh seedsby artisanal methods without any preliminary processing. It was preserved at room temperature in a bottle made of brown glass.

\subsection{Behavioral Testing}

At the end of the supplementation period, all animals underwent behavioral testing. OF, EPM then FST were performed in the morning of three consecutive days. 


\section{-Open Field test (OF)}

The investigatory behavior was tested in a wooden made apparatus $(100 \mathrm{~cm} \times 100 \mathrm{~cm})$. As previously reported [11], it was enclosed with $40 \mathrm{~cm}$ high walls and placed under strong illumination $(100 \mathrm{~W}, 2 \mathrm{~m}$ above the apparatus). The area was divided into 25 squares $(20 \mathrm{~cm} \times 20 \mathrm{~cm})$, defined as 9 central and 16 peripheral squares. At the beginning of the 10-min test, the animal was placed in the center of the apparatus and its behavior was video-taped for subsequent analysis. The device was cleaned after each individual rat session. The quantified parameters were the time spent in the center of the area and the number of returns to the nine square central sections. Central perimeter residence time is used as measure of anxiety [12]. The number of returns to the central area is also an indicator of the emotional reactivity [11]. The central area of a novel environment is anxiogenic and aversive and the behavioral inhibition appears therefore as an avoidance behavior towards the central zone of the open field [13]. The apparatus was cleaned between each examination using $70 \%$ ethyl alcohol.

\section{-Elevated Plus Maze test (EPM)}

The EPM is an ethological model of anxiety in rodents provoked by the novelty and repulsion as a result of elevation and illumination of the maze [14]. This test is based on the creation of a conflict between the exploratory drive of the rat and its innate fear of open and exposed areas; it has been validated for the detection of emotional responses to anxiogenic and anxiolytic substances [15]. Thus, increased open-arms exploration indicates reduced anxiety-related behavior. The EPM consists of a wooden plus-shaped platform elevated $70 \mathrm{~cm}$ above the floor. Two of the opposing arms $(50 \mathrm{~cm} \times 10 \mathrm{~cm})$ are closed by $40 \mathrm{~cm}$ high side and end walls, having an open roof. In order to avoid fall, the other two arms (open arms) were surrounded by $0.5 \mathrm{~cm}$ high edge, the four arms had at their intersection a central platform $(10 \mathrm{~cm} \times 10 \mathrm{~cm})$. A 100 -W lamp was placed exactly over the central platform. At the beginning of the test, the rats were placed on the central area of the maze facing an open arm. The following parameters of anxiety-related behavior were measured during the 5 min testing period: 1) entries into open arms, 2) time spent in open arms, 3) and number of full entries into the arms. Decreased anxiety-like behavior is illustrated by a significant statistical increase of parameters in open arms (time and/or entries). Although, entries in closed arms and total entries reflect the motor component of the exploratory activity. To eliminate any lingering olfactory cues, the apparatus was cleaned between each examination using $70 \%$ ethyl alcohol.

\section{-Forced Swim Test (FST)}

The method followed was described by Porsolt and al. [16]. To assess depressive-like responses, rats were individually placed in a cylinder (height $=50 \mathrm{~cm}$; diameter $=30 \mathrm{~cm}$ ) containing $27 \mathrm{~cm}$ water $\left(22^{\circ} \mathrm{C}\right)$ from which they could not escape. The rats were placed in the water for $5 \mathrm{~min}$ and the duration of immobility was measured. The latency to the first bout of immobility was also recorded starting immediately after placing the rats in the cylinders. A rat was judged immobile when it ceased all active behaviors (i.e. struggling, swimming and jumping) and remained passively floating or making minimal movements necessary to maintain the nostrils above water. High percent time floating is interpreted as an increased depressive-like response.

\subsection{Blood Collection, Biochemical and Hematological Profiles Determination}

At the end of testing period and after 13 weeks of treatment and an overnight fasting (10 - 12 hours), the animals After 13 weeks of treatment and an overnight fasting (10 - 12 hours), the animals were anesthetized with Choral $7 \%(0.5 \mathrm{~mL} / 100 \mathrm{~g})$ then killed.

Subsequently, venous blood samples of all rats were collected at 8:30 - 9:30 am in the morning. Two mL of blood samples was immediately transferred to ethylendiaminetetraacetate (EDTA) tubes for measurement of hematological parameters. The remaining blood was put into a dry tube for serum extraction and analysis of biochemical profile. The tubes were kept at $4^{\circ} \mathrm{C}$ and all analyses were done twice.

Blood samples were collected in order to determine the biochemical profile. Adopting the method of Tietz et al (1994), the levels transaminases, cholesterol and high-density lipoprotein cholesterol (HDL-C) were determined in the serum using assay kits from Roche Diagnostics on Roche Modular (model P800) Mannhein, Germany. For glycemia and triglycerides, tests were performed according to the methodology proposed by commercial kits: LABTEST (Lagoa Santa, Belo Horizonte, MG). Low density lipoprotein cholesterol (LDL-C) was determined by Friedwald formula:

$$
\text { LDL-cholesterol }=\text { TC }-(\text { HDL }+ \text { TG/5) }
$$


Corticosterone was measured by ELISA method (IBL International).

Haematologic profiles involving complete blood counts were determined using an automatic cell counter (Drew Scientific, Excell-18; Minnesota, USA). Detailed procedures and data analysis are described elsewhere [17].

\subsection{Adrenal Histology}

After macroscopic examination of adrenal previously fixed in $10 \%$ buffered formalin, fragments were then dried gradually in ethanol solutions. The tissue specimen was embedded in paraffin; $5 \mu \mathrm{m}$ thick serial histologic sections were obtained from the paraffin blocks by using a microtome. We carried out three slices on each block. Staining was performed by the Hematoxylin-Phloxine-Saffron (HPS). To highlight any differences in size of morphological elements, adrenal slices were observed at several magnifications (5, 10 and 20).

\subsection{Data Analysis}

To determine the differences between control and treated groups, statistical analysis was performed by analysis of variance (ANOVA). The comparison of the means and their ranking was realized by the Duncan test whenever the analysis of variance showed significant differences.

Differences were considered significant when $p<0.05$, very significant when $p<0.01$ and highly significant when $p<0.001$.

\section{Results}

\subsection{Behavioral Testing}

Behavioral tests allowed evaluation of animals ambulatory activity and reactivity when facing stressful experiences such as a large and very bright square (OF), an elevated area (EPM) and a filled with water space (FST). Table 1 summarizes all results.

Supplementation affected significantly number of recoveries, number of returns to central area, time spent in open arm and immobility time in males. Also, total number of entries in all arms and especially open ones were very significantly modified by supplementation. All parameters increased in supplemented male rats except immobility time which decreased.

In females, number of recoveries and immobility time are very significantly influenced by argan oil 13 weeks supplementation, total numbers of entries in all arms is highly modified and time spent in open arms was

Table 1. Performances of rats in behavioral tests. Times are measured in seconds.

\begin{tabular}{|c|c|c|c|c|c|}
\hline \multirow[b]{2}{*}{ Parameter of behavioral test } & \multicolumn{2}{|c|}{ Control animals } & \multicolumn{2}{|c|}{ Supplemented animals } & \multirow[b]{2}{*}{$p$} \\
\hline & Mean & $\begin{array}{l}\text { Standard } \\
\text { Deviation }\end{array}$ & Mean & $\begin{array}{l}\text { Standard } \\
\text { Deviation }\end{array}$ & \\
\hline Number of Excrements (OF) & $\begin{array}{l}\Im 70 \\
+0.1\end{array}$ & $\begin{array}{l}\stackrel{\jmath}{\jmath} 0 \\
+0.22\end{array}$ & $\begin{array}{l}\Im 0 \\
+0.4\end{array}$ & $\begin{array}{l}\delta^{1} 0 \\
+0.6\end{array}$ & 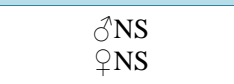 \\
\hline Number of recoveries (OF) & $\begin{array}{l}38 \\
+5.6\end{array}$ & $\begin{array}{l}\text { o1.23 } \\
+2.6\end{array}$ & $\begin{array}{l}\Im 12 \\
+11\end{array}$ & $\begin{array}{l}\Im 1.5 \\
\varnothing 0.8\end{array}$ & $\begin{array}{l}\Im 0.01<p<0.05^{*} \\
+0.001<p<0.01^{*}\end{array}$ \\
\hline Number of returnsin central area (OF) & $\begin{array}{l}38 \\
+8.4\end{array}$ & $\begin{array}{l}\Im 1.5 \\
+1.94\end{array}$ & $\begin{array}{l}\uparrow 10 \\
+9\end{array}$ & $\begin{array}{l}\jmath 1.4 \\
+2.64\end{array}$ & 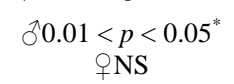 \\
\hline Time spent in central area (OF) & $\begin{array}{l}391 \\
+95\end{array}$ & $\begin{array}{l}\jmath 11.03 \\
+6.55\end{array}$ & $\begin{array}{l}ð 100 \\
+90.2\end{array}$ & $\begin{array}{l}35.65 \\
+17.83\end{array}$ & $\begin{array}{l}\jmath \mathrm{NS} \\
\text { †NS }\end{array}$ \\
\hline Total number of entries in all arms (EPM) & $\begin{array}{l}\Im 13 \\
+9\end{array}$ & $\begin{array}{l}\text { 乃3.02 } \\
\text { +2.07 }\end{array}$ & \begin{tabular}{c} 
\} 2 6 $\\
{+21.66}$ & $\begin{array}{l}78.13 \\
+4.5\end{array}$ & $\begin{array}{c}\widehat{T} 0.001<p<0.01^{*} \\
+p<0.001^{* * *}\end{array}$ \\
\hline Time spent in open arms (EPM) & $\begin{array}{l}\Im 40 \\
+33.4\end{array}$ & $\begin{array}{c}\text { †3 } 33.67 \\
\quad+3\end{array}$ & $\begin{array}{l}\bigcirc 71.5 \\
\Varangle 75.2\end{array}$ & $\begin{array}{l}\text { \15.02 } \\
\text { 1 } 19.04\end{array}$ & $\begin{array}{l}\precsim 0.01<p<0.05^{*} \\
+0.01<p<0.05^{*}\end{array}$ \\
\hline Number of entries in open arms (EPM) & $\begin{array}{l}\not 3 \\
+7.4\end{array}$ & $\begin{array}{l}30.21 \\
\not 2.07\end{array}$ & $\begin{array}{l}\nwarrow 11 \\
+4.3\end{array}$ & $\begin{array}{l}\Im 1.92 \\
+2.08\end{array}$ & 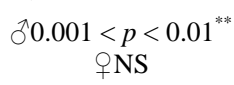 \\
\hline Time of immobility (FST) & $\begin{array}{l}738 \\
+60\end{array}$ & $\begin{array}{l}\Im 3.8 \\
+3.07\end{array}$ & $\begin{array}{l}135.6 \\
946.2\end{array}$ & $\begin{array}{l}74.26 \\
+6.45\end{array}$ & $\begin{array}{l}\Im 0.01<p<0.05^{*} \\
+0.001<p<0.01^{* *}\end{array}$ \\
\hline
\end{tabular}
\end{tabular}

p: Probability; NS: Non significant; ${ }^{*}$ : Significant; ${ }^{* *}$ : Very significant; ${ }^{* * *}$ : Highly significant. Six males and six females Wistar rats tested. 
significantly changed. Like in males, all these parameters increased in supplemented females but the trend is reversed for immobility which was the only sex-dependent parameter, indeed, females left significantly more immobile in FST than males.

All data concerning locomotor activity like number of recoveries in OF and number of entries in all arms in EPM showed that supplemented rats move more vigorously than controls. Also, those rats seem fearless and more likely to adapt to stressful events with regard to their performances in EPM and FST.

Thus, argan oil supplementation seems to strengthen ambulatory activity and enhance resistance to frightening situation. Immobility time in FST is the only parameter that varies significantly by gender.

\subsection{Histology}

At low magnification and with HPS staining, the adrenal appears consisting of a cortex, an inner medulla slightly colored and a capsule that provides external support to the delicate structure of secretory cells.

In adrenal slices, a slight hypertrophy was observed in the cortex of supplemented rats (Figure 1).

The thickness of the cortex is proportional to its secretory activity, thus its hypertrophy reflects an increased hormone secretion. Despite the fact that all three layers comprising the cortex are not easily discernible, the "zonafasciculata" is whose secretions are most correlating with corticosterone assays whose rate tends to increase in stressed animals (Table 2).

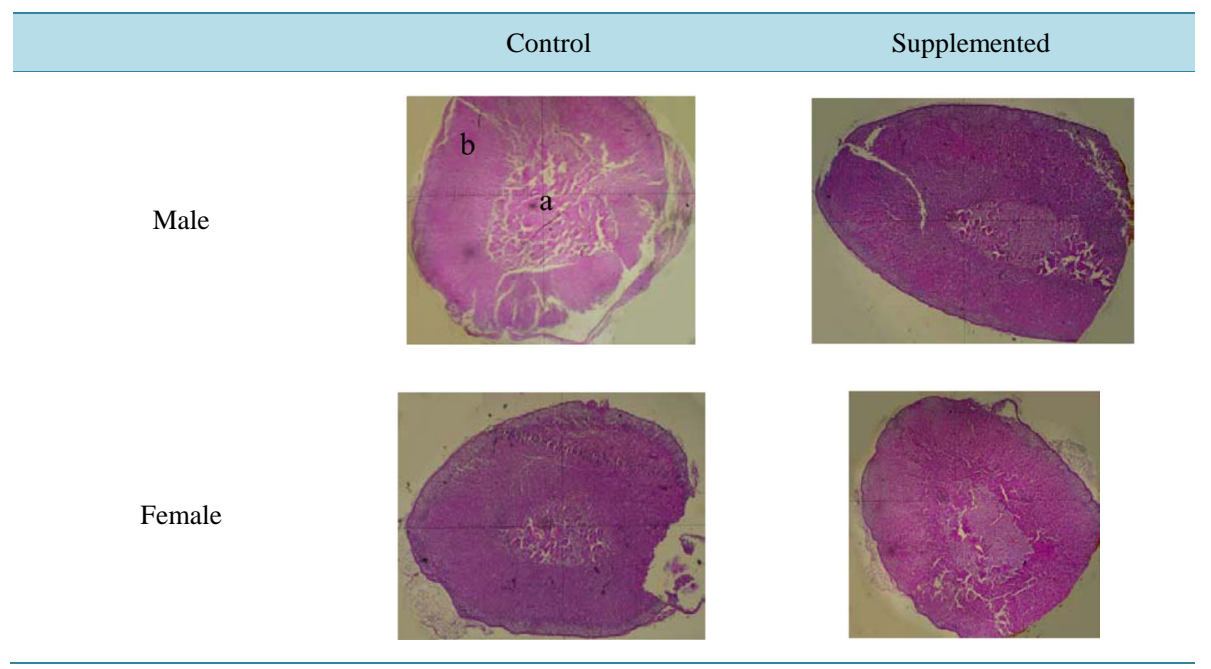

Figure 1. Adrenal slices. Three slices were performed on each gland of six males and six females Wistar rats. a: medulla, b: cortex. All observation are made at $\times 5$ magnification time.

Table 2. Biochemical profile of rats.

\begin{tabular}{|c|c|c|c|c|c|}
\hline \multirow[b]{2}{*}{ Parameter } & \multicolumn{2}{|c|}{ Control animals } & \multicolumn{2}{|c|}{ Supplemented animals } & \multirow{2}{*}{$p$} \\
\hline & Mean & Standard Deviation & Mean & Standard Deviation & \\
\hline Glycemia (g/l) & $\begin{array}{l}\$ 2.02 \\
+1.99\end{array}$ & $\begin{array}{l}\$ 0.21 \\
+0.40\end{array}$ & $\begin{array}{l}72.18 \\
+2.04\end{array}$ & $\begin{array}{l}70.24 \\
+0.22\end{array}$ & $\begin{array}{l}\text { ठNS } \\
\text { †NS }\end{array}$ \\
\hline $\begin{array}{c}\mathrm{LDL} \\
(\mathrm{mmol} / \mathrm{l})\end{array}$ & $\begin{array}{l}\Im 0.28 \\
+0.29\end{array}$ & $\begin{array}{l}{ }^{\top} 0.21 \\
\subsetneq 0.08\end{array}$ & $\begin{array}{l}\bigcirc 0.30 \\
+0.33\end{array}$ & $\begin{array}{l}70.04 \\
+0.10\end{array}$ & $\begin{array}{l}\not N \mathrm{NS} \\
\text { †NS }\end{array}$ \\
\hline $\begin{array}{c}\mathrm{HDL} \\
(\mathrm{mmol} / \mathrm{l})\end{array}$ & $\begin{array}{l}\Im 0.26 \\
+0.40\end{array}$ & 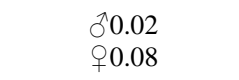 & $\begin{array}{l}\$ 0.26 \\
+0.32\end{array}$ & $\begin{array}{l}30.02 \\
+0.02\end{array}$ & $\begin{array}{l}\text { ठNS } \\
\text { oNS }\end{array}$ \\
\hline $\begin{array}{c}\text { TGC } \\
(\mathrm{mmol} / \mathrm{l})\end{array}$ & \begin{tabular}{l} 
\} 0 . 4 1 $\\
{\subsetneq 0.50}$ & 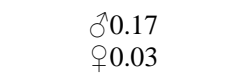 & $\begin{array}{l}\$ 0.40 \\
\subsetneq 0.76\end{array}$ & $\begin{array}{l}\$ 0.26 \\
+0.12\end{array}$ & $\begin{array}{c}\stackrel{\lambda}{N} \mathrm{NS} \\
q 0.01<p<0.05^{*}\end{array}$ \\
\hline Corticosterone (ng/ml) & $\begin{array}{l}\text { ○0 } 0.66 \\
+0.83\end{array}$ & 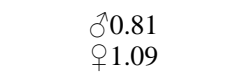 & $\begin{array}{l}\text { ○1.20 } \\
+1.72\end{array}$ & $\begin{array}{l}\bigcirc 0.28 \\
+0.54\end{array}$ & $\begin{array}{l}\text { oNS } \\
\text { oNS }\end{array}$ \\
\hline
\end{tabular}
\end{tabular}

p: Probability; NS: Non significant; ${ }^{*}$ : Significant; ${ }^{* *}$ : Very significant; ${ }^{* * *}$ : Highly significant. Analyses were performed on blood samples from six males and six females Wistar rats. All analyses were repeated twice. 


\subsection{Biochemistry}

In order to assess modification of biochemical parameter in rats supplemented for 13 weeks by argan oil, biochemical analyses were performed on blood sample. Table 2 shows that despite the increase in TGC level in females, 13 weeks argan oil administration induced no change in biochemical profile.

Corticosterone was measured with the aim to evaluate emotions related to stress in supplemented rats. Rates showed no significanceal though this rate has a tendency to increase in supplemented animals.

\subsection{Blood Cell Count}

With the aim to reveal changes in blood cells induced by particular diet, we performed a blood cell counts (Table 3). In spite of lymphocytes rates which significantly increased in females and decreased in males along with a low level of eosinophiles, any noticeable change in hematological profile of 13 weeks argan oil supplemented rats have been induced.

\section{Discussion}

Diet is one of the environmental factors susceptible to develop or reduce susceptibility to diseases [18]. Argan oil is well known for its beneficial effect as hypolipemiant, hypotensive and antioxidant activities [19]. The protective effect of argan oil could be attributed to its interesting chemical composition. It is essentially characterized by the presence of unsaturated fatty acids and antioxidant compounds such as Vitamin E family (tocopherol).

In this work, we aimed to study argan oil supplementation benefits on stress related diseases (anxiety and depression) and correlate it to adrenal histology in addition to changes on some metabolic and blood panel markers.

Regarding behaviour, nutritional factors are neglected partly because nutritional deficiencies are not expected to affect the behavior despite evidence increasingly suggests that this belief may be wrong. In fact, mediterranean, whole food diets have been associated with modulation of cognitive function and mental health [20] and neuropsychological impairment confirmed by electroencephalography recordings of elderly has been associated with a number of nutritional deficiencies [21].

In our study, behavioral performances of supplemented rats showed the existence of changes in behavior. It appears that locomotor activity of supplemented rats and their exploration of the central area and open arms in creased compared to control rats. Also, they spend less time immobile in FST. Some animal performance in the tests vary according to sex, reduced immobility time in supplemented females was the most relevant one suggesting greater receptivity to supplementation in females than in males. It is therefore concluded that nutritional

Table 3. Haematological profile of rats.

\begin{tabular}{|c|c|c|c|c|c|}
\hline \multirow[b]{2}{*}{ Parameter } & \multicolumn{2}{|c|}{ Control animals } & \multicolumn{2}{|c|}{ Supplemented animals } & \multirow{2}{*}{$p$} \\
\hline & Mean & Standard Deviation & Mean & Standard Deviation & \\
\hline White cells $\left(\mathrm{m} / \mathrm{mm}^{3}\right)$ & $\begin{array}{l}34.32 \\
+2.98\end{array}$ & $\begin{array}{l}\Im 1.21 \\
+0.48\end{array}$ & $\begin{array}{l}\Im 4.54 \\
+5.27\end{array}$ & $\begin{array}{l}\text { ठ⒈32 } \\
+1.40\end{array}$ & 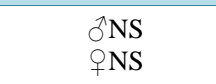 \\
\hline Lymphocytes (m/mm³) & $\begin{array}{l}\jmath 63.33 \\
+65.66\end{array}$ & $\begin{array}{l}74.16 \\
+7.1\end{array}$ & $\begin{array}{l}\jmath^{1} 56.66 \\
+75.33\end{array}$ & $\begin{array}{l}\Im 7.76 \\
+6.42\end{array}$ & $\begin{array}{l}\gamma 0.01<p<0.05^{*} \\
+0.01<p<0.05^{*}\end{array}$ \\
\hline Monocytes $\left(\mathrm{m} / \mathrm{mm}^{3}\right)$ & $\begin{array}{l}\text { J1.33 } \\
+2\end{array}$ & 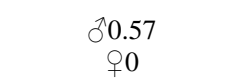 & $\begin{array}{l}\grave{\jmath} 4.33 \\
\text { ○1.33 }\end{array}$ & $\begin{array}{l}\nearrow 4.04 \\
+0.57\end{array}$ & $\begin{array}{l}\precsim \mathrm{NS} \\
\text { ○्रS }\end{array}$ \\
\hline Eosinophiles $\left(\mathrm{m} / \mathrm{mm}^{3}\right)$ & $\begin{array}{c}32.33 \\
+93\end{array}$ & $\begin{array}{c}30.57 \\
\subsetneq 0\end{array}$ & $\begin{array}{c}35 \\
+03.66\end{array}$ & 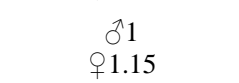 & $\begin{array}{c}\precsim 0.01<p<0.05^{*} \\
\text { q NS }\end{array}$ \\
\hline Basophiles $\left(\mathrm{m} / \mathrm{mm}^{3}\right)$ & $\begin{array}{l}30.66 \\
+0.66\end{array}$ & $\begin{array}{l}\$ 0.57 \\
+0.57\end{array}$ & $\begin{array}{l}\Im 0.33 \\
+0.66\end{array}$ & $\begin{array}{l}70.57 \\
\bigcirc 0.57\end{array}$ & 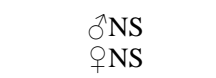 \\
\hline Red blood cells $\left(\mathrm{m} / \mathrm{mm}^{3}\right)$ & $\begin{array}{l}37.62 \\
07.16\end{array}$ & $\begin{array}{l}\Im 70.49 \\
+0.22\end{array}$ & $\begin{array}{l}\text { ○7 } 7.66 \\
+7.17\end{array}$ & $\begin{array}{l}10.42 \\
+0.42\end{array}$ & $\begin{array}{l}\text { ons } \\
\text { ONS }\end{array}$ \\
\hline Platelets $\left(\mathrm{m} / \mathrm{mm}^{3}\right)$ & $\begin{array}{l}7619 \\
+590\end{array}$ & $\begin{array}{l}\delta^{\lambda} 240.9 \\
+69.19\end{array}$ & $\begin{array}{l}3476 \\
+553\end{array}$ & $\begin{array}{l}\text { on169.99 } \\
+28.82\end{array}$ & $\begin{array}{l}\text { ôNS } \\
\text { OTS }\end{array}$ \\
\hline
\end{tabular}

p: Probability; NS: Non significant; ${ }^{*}$ : Significant; ${ }^{* *}$ : Very significant; ${ }^{* * *}$ : Highly significant. Analyses were performed on blood samples from six males and six females Wistar rats. All analyses were repeated twice. 
supplementation induced a resistance to stressful environments as OF, EPM and FST. These effects can also be considered as an anxiolytic-like and an antidepressive-like effects since OF, EPM and FST are behavioral tests intended to evaluate anxiety and depression states. Thus, supplementation caused long-term changes in the emotional behavior of adult rats of both sexes, although to a differing degree in males and females, whereas it appeared to cause predominantly variations in males, depending on the behavioral test used. These results suggest a role for sex hormones in mediating sex differences in sensitivity to frightening environments, although other possible mechanisms remain to be investigated.

The composition of argan can facilitate healthy brain by providing antioxidants, polyinsatured fatty acids and vitamins that would influence cellular functions involved in the synaptic transmission [22], neurite growth [23], membrane fluidity [24] and neurodegeneration [25]. These effects may have been more relevant here since argan supplementation has begun in an early age (just after weaning) during which neural networks continue to settle.

Polyinsatured fatty acids are particularly involved in a better resistance to behavioral stress. Many studies have suggested their beneficial role in psychological illnesses such as depression or anxiety disorders, which are described as being related to stress [26].

Moreover, slight changes in hematological profile of 13 weeks argan oil supplemented rats have been observed concerning on overall white blood cells. Only a few studies have specifically investigated factors that influence blood cell count, among these: sex [27] and also genetic and environmental factors including diet which modify size and number of blood cells [28].

Rates of corticosterone measured to evaluate stress-related emotions in supplemented rats showed no significance. However, adrenal slices showed a slight hypertrophy in the cortex of supplemented rats. These data correlate with a stress state but in the same time are inconsistent with rats' performances in behavioral tests. In fact, the general adaptation syndrome in response to stress involves a complex pathophysiology which depends on the Hypothalamus-Pituitary-Adrenal axis hormones secretion that is regulated with two feed-backs.

The present finding, associated with the white blood cell profile reported (Table 3), strengthen clinical studies that have reported beneficial anti-inflammatory effects of argan oil in some pathologic conditions [29]. May beneficial effects against inflammatory disorders, led by argan oil, be due to the particular profile of white blood cell and the induction of glucocorticoid secretion (corticosterone, which has an anti-inflammatory activity).

In 13 weeks argan oil supplemented rats, only a high rate in TGC level in females have been noticed. Drissi et al. [2] provide first evidence of hypolipemiant and antioxidant properties of argan oil in human and demonstrate that argan oil offers an additional product to reduce cardiovascular risk factors and retard the onset of the atherosclerosis process. Thus, our results that appear inconsistent with the effects of the commonly described argan oil effects in literature may be due, on the one hand to the length of the period of supplementation (13 weeks) and on the other hand to the few studies that have specifically investigated the benefit of a dietary intake of argan oil on biochemical parameters.

Furthermore, nutrition remains one of the most important environmental factors to promote epigenetic alterations in an individual, especially exposure to plant compounds. Phytochemicals have effects on cellular signaling events, so they have the capacity to modify developmental and physiological events and impacts on the health of future generations [30]. Areas of evolutionary biology have not yet considered an epigenetic effect of argan oil which could partly explain the few upheaval noticed in supplemented rats.

\section{Conclusion}

In conclusion, further investigations concerning the mechanism by which argan oil impacts on biochemical and hematological profile as well as stress related behavior would be necessary. Our study suggests for the first time that argan oil components could play a role in mental health and in developing new strategies for the prevention and treatment of stress related disorders that involves herbal psychopharmacology. Several studies showed that tocopherols, phytosterols, and polyphenols exert beneficial effects in addition to unsaturated fatty acids. Knowing the interesting chemical composition of argan oil and the complexity of stress pathophysiology which involves nervous and immune system as well as metabolism, we can consider the possible synergistic effects of these compounds that would be more beneficial than the use of each one.

\section{Acknowledgements}

Authors would like to thank Dr Rhazali Jahidi, Dr Harmouch and Dr Lotfi for their technical support as well as CNRST Morocco for financial support. 


\section{References}

[1] Boukhobza, M. and Pichon-Prun, N. (1988) L’arganier ressource économique et medicinale pour le Maroc. Phytothérapie, 27, 21-26.

[2] Drissi, A., Girona, J., Cherki, M., Godas, G., Derouiche, A. and El Messal, M. (2004) Evidence of Hypolipemiant and Antioxidant Properties of Argan Oil Derived from the Argan Tree (Arganiaspinosa). Clinical Nutrition, 23, 1159-1166. http://dx.doi.org/10.1016/j.clnu.2004.03.003

[3] Chimi, H., Cillard, J. and Cillard, P. (1994) Autoxydation dec l'huile d’argan (Argania spinosa) sapotaceae du Maroc. Sciences des Aliments, 14, 117-24.

[4] Berrougui, H., De Sotomayor, M.A., Perez-Guerrero, C., Ettaib, A., Hmamouchi, M., Marhuenda, E. and Herrera, M.D. (2004) Argan (Arganiaspinosa) Oil Lowers Blood Pressure and Improves Endothelial Dysfunction in Spontaneously Hypertensive Rats. British Journal of Nutrition, 92, 921- 929. http://dx.doi.org/10.1079/BJN20041293

[5] Bennani, H., Drissi, A., Giton, F., Kheuang, L., Fiet, J. and Adlouni, A. (2007) Antiproliferative Effect of Polyphenols and Sterols of Virgin Argan Oil on Human Prostate Cancer Cell Lines. Cancer Detection and Prevention, 31, 64-69. http://dx.doi.org/10.1016/j.cdp.2006.09.006

[6] El Monfalouti, H., Guillaume, D., Denhez, C. and Charrouf, Z. (2010) Therapeutic Potential of Argan Oil: A Review. Journal of Pharmacy and Pharmacology, 62, 1669-1675. http://dx.doi.org/10.1111/j.2042-7158.2010.01190.x

[7] Sable, P., Dangat, K., Kale, A. and Joshi, S. (2011) Altered Brain Neurotrophins at Birth: Consequence of Imbalance in Maternal Folic Acid and Vitamin B12 Metabolism. Neuroscience, 190, 127-134. http://dx.doi.org/10.1016/j.neuroscience.2011.05.010

[8] Vijay-Kumar, M., Vanegas, S.M., Patel, N., Aitken, J.D., Ziegler, T.R. and Ganji, V. (2011) Fish Oil Rich Diet in Comparison to Saturated Fat Rich Diet Offered Protection against Lipopolysaccharide-Induced Inflammation and Insulin Resistance in Mice. Nutrition Metabolism, 8, 16. http://dx.doi.org/10.1186/1743-7075-8-16

[9] Bouayed, J. (2010) Polyphenols: A Potential New Strategy for the Prevention and Treatment of Anxiety and Depression. Current Nutrition \& Food Science, 6, 13-18. http://dx.doi.org/10.1186/1743-7075-8-16

[10] Mekhfi, H., Belmekki, F., Ziyyat, A., Legssyer, A., Bnouham, M. and Aziz, M. (2012) Antithrombotic Activity of Argan Oil: An in Vivo Experimental Study. Nutrition, 28, 937-941. http://dx.doi.org/10.1016/j.nut.2011.11.032

[11] Durand, M., Berton, O., Aguere, S., Edno, L., Combourieu, I., Mormede, P. and Chaouloff, F. (1999) Effects of Repeated Fluoxetine on Anxiety Related Behaviours, Central Serotonergic Systems, and the Corticotropic Axis in SHR and WKY Rats. Neuropharmacology, 38, 893-907. http://dx.doi.org/10.1016/S0028-3908(99)00009-X

[12] Nasselo, A.G., Machado, C., Bastos, J.F. and Felicio, L. (1998) Sudden Darkness Induces a High Activity-Low Anxiety State in Male and Female Rats. Physiology \& Behavior, 63, 451-454. http://dx.doi.org/10.1016/S0031-9384(97)00462-9

[13] Meyer, L., Caston, J. and Mensah-Nyagan, A. (2006) Seasonal Variation of the Impact of a Stressful Procedure on Open Field Behaviour and Blood Corticosterone in Laboratory Mice. Behavioural Brain Research, 167, 342-348. http://dx.doi.org/10.1016/j.bbr.2005.09.023

[14] Clenet, F., Bouyon, E., Hasco, M. and Bourin, M. (2006) Light/Dark Cycle Manipulation Influences Mice Behavior in the Elevated Plus Maze. Behavioural Brain Research, 166, 140-149. http://dx.doi.org/10.1016/j.bbr.2005.07.018

[15] Pellow, S., Chopin, P., File, S.E. and Briley, M. (1985) Validation of Open: Closed Arms Entries in an Elevated PlusMaze as a Measure of Anxiety in the Rat. Journal of Neuroscience Methods, 14, 149-167. http://dx.doi.org/10.1016/0165-0270(85)90031-7

[16] Porsolt, R.D., Anton, G., Blavet, N. and Jalfre, M. (1978) Behavioural Despair in Rats: A New Model Sensitive to Antidepressant Treatments. European Journal of Pharmacology, 47, 379-391. http://dx.doi.org/10.1016/0014-2999(78)90118-8

[17] Woo, S., Krzyzanski, W. and Jusko, W.J. (2008) Pharmacodynamic Model for Chemotherapy-Induced Anemia in Rats. Cancer Chemotherapy and Pharmacology, 62, 123-133. http://dx.doi.org/10.1007/s00280-007-0582-9

[18] Link, A., Balaguer, F. and Goel, A. (2010) Cancer Chemoprevention by Dietary Polyphenols: Promising Role for Epigenetics. Biochemical Pharmacology, 80, 1771-1792. http://dx.doi.org/10.1016/j.bcp.2010.06.036

[19] Cherki, M., Berrougui, H., Drissi, A., Adlouni, A. and Khalil, A. (2006) Argan Oil: Which Benefits on Cardiovascular Diseases? Pharmacological Research, 54, 1-5. http://dx.doi.org/10.1016/j.phrs.2006.02.004

[20] Parletta, N., Milte, C.M. and Meyer, B.J. (2013) Nutritional Modulation of Cognitive Function and Mental Health. Journal of Nutritional Biochemistry, 24, 725-743. http://dx.doi.org/10.1016/j.jnutbio.2013.01.002

[21] Denis, I., Potier, B., Vancassel, S., Heberden, C. and Lavialle, M. (2013) Omega-3 Fatty Acids and Brain Resistance to Ageing and Stress: Body of Evidence and Possible Mechanisms. Ageing Research Reviews, 12, 579-594.

http://dx.doi.org/10.1016/j.arr.2013.01.007 
[22] Anderson, G.H. (1981) Diet, Neurotransmitters and Brain Function. British Medical Bulletin, 37, 95-100.

[23] Futerman, A.H. and Banker, G.A. (1996) The Economics of Neurite Outgrowth-The Addition of New Membrane to Growing Axons. Trends in Neurosciences, 19, 144-149. http://dx.doi.org/10.1016/S0166-2236(96)80025-7

[24] Nealon, J.R., Blanksby, S.J., Mitchell, T.W. and Else, P.L. (2008) Systematic Differences in Membrane Acyl Composition Associated with Varying Body Mass in Mammals Occur in All Phospholipid Classes: An Analysis of Kidney and Brain. The Journal of Experimental Biology, 211, 3195-204. http://dx.doi.org/10.1242/jeb.019968

[25] Ledesma, M.D., Martin, M.G. and Dotti, C.G. (2012) Lipid Changes in the Aged Brain: Effect on Synaptic Function and Neuronal Survival. Progress in Lipid Research, 51, 23-35. http://dx.doi.org/10.1016/j.plipres.2011.11.004

[26] Liperoti, R., Landi, F., Fusco, O., Bernabei, R. and Onder, G. (2009) Omega-3 Polyunsaturated Fatty Acids and Depression: A Review of the Evidence. Current Pharmaceutical Design, 15, 4165-4172. http://dx.doi.org/10.2174/138161209789909683

[27] Herrick, E.H., Lockhart, C.H., Martin, E.P. and Nusser, W.L. (1954) Influence of Sex Hormones on Blood Cell Counts and Hemoglobin Levels in Fowls. Transactions of the Kansas Academy of Science, 57, 483-492. http://dx.doi.org/10.2307/3625933

[28] Whitfield, J.B. and Martin, N.G. (1985) Genetic and Environmental Influences on the Size and Number of Cells in the Blood Genetic. Epidemiology, 2, 133-144.

[29] Benzaria, A., Meskini, N., Dubois, M., Croset, M., Némoz, G., Lagarde, M. and Prigent, A.F. (2006) Effect of Dietary Argan Oil on Fatty Acid Composition, Proliferation, and Phospholipase D Activity of Rat Thymocytes. Nutrition, 22, 628-637. http://dx.doi.org/10.1016/j.nut.2006.03.001

[30] Guerrero-Bosagna, C.M. and Skinner, M.K. (2014) Environmental Epigenetics and Phytoestrogen/Phytochemical Exposures. Journal of Steroid Biochemistry \& Molecular Biology, 139, 270-276.

http://dx.doi.org/10.1016/j.jsbmb.2012.12.011

\section{Abbreviation List}

OF: Open Field Test;

EPM: Elevated Plus Maze;

FST: Forced Swimming Test;

LDL: Low Density Lipoprotein;

HDL: High Density Lipoprotein;

HPS: Hematoxylin-Phloxine-Saffron. 